\title{
Evolução do financiamento da atenção à saúde bucal no SUS: uma análise do processo de reorganização assistencial frente aos incentivos federais
}

\author{
I 1 George Edward Machado Kornis, ${ }^{2}$ Leila Senna Maia, \\ ${ }^{3}$ Renata Ferraiolo Peixoto Fortuna I
}

Resumo: O trabalho descreve e analisa, na perspectiva do financiamento federal, o desenvolvimento da Política Nacional de Saúde Bucal (PNSB). O artigo considera o avanço no sentido da ampliação do acesso representado pela inserção das Equipes de Saúde Bucal (ESBs) na Estratégia Saúde da Família (ESF) e a criação dos Centros de Especialidades Odontológicas (CEOs) e dos Laboratórios Regionais de Prótese Dentária (LRPDs). Não obstante a importância da ampliação desse acesso, o objetivo deste trabalho é refletir sobre a seguinte questão: de que forma e em que medida a Portaria no 302/2009, que desvincula as EBSs da ESF, será capaz de garantir a manutenção do acesso já conquistado com continuidade do aporte de recursos financeiros? Para tal fim, foi realizada análise bibliográfica e documental abrangendo os períodos de vigência das Normas Operacionais do SUS até a edição do Pacto pela Saúde 2006. Nas considerações finais, os autores destacam que o maior aporte de recursos financeiros voltado para a atenção à saúde bucal está em sintonia com as políticas adotadas pelo Ministério da Saúde (MS) na década de 1990: a reorganização da Atenção Básica através da ESF e a política de incentivos, como forma de repasse de recursos federais. Ainda é destacado o risco de retrocesso representado pela edição da referida Portaria, no sentido de comprometer tanto o processo de reorganização da atenção básica em SB quanto seu financiamento, uma vez que a política de incentivos do MS é voltada para esta Estratégia.

> Palavras-chave: Saúde Bucal, SUS, política de saúde, Política Nacional de Saúde Bucal, financiamento.

\author{
1 Professor adjunto no \\ Departamento de Planejamento \\ e Administração de Saúde \\ do IMS-UERJ; Economista; \\ mestre e doutor em Economia \\ pelo Instituto de Economia da \\ Universidade Federal do Rio de \\ Janeiro. Endereço eletrônico: \\ kornis@ims.uerj.br. \\ ${ }^{2}$ Cirurgiã-dentista; especialista \\ em Odontopediatria pela \\ Policlínica Geral do Rio de \\ Janeiro; especialista em \\ Programa de Saúde da Família \\ pelo Consórcio MS/EURJ-"PSF- \\ RJ"; mestre e doutoranda em \\ Saúde Coletiva pelo IMS-UERJ. \\ Endereço eletrônico: senna. \\ maia@click21.com.br \\ ${ }^{3}$ Cirurgiã-dentista; especialista \\ em Endodontia pela Faculdade \\ de Odontologia de Campos; \\ mestre e doutoranda em \\ Saúde Coletiva pelo IMS- \\ UERJ. Endereço eletrônico: \\ renataferraiolo@hotmail.com.
}

Recebido em: 11/09/2009. Aprovado em: 30/04/2010. 
A Portaria do Gabinete do Ministro da Saúde no 302, de fevereiro de 2009, estabeleceu que Equipes de Saúde Bucal (ESBs) poderiam ser incorporadas às Equipes de Agentes Comunitários de Saúde (EACSs), desde que observados os mesmos pré-requisitos de incorporação de profissionais de saúde bucal nas Equipes de Saúde da Família (ESFs) (BRASIL, 2009a) O Ministério da Saúde (MS) pretendia, com essa portaria, ampliar a cobertura da população por ESBs em uma escala próxima à cobertura oferecida pela ESF (APCD, 2009). Em 30 de abril de 2009, a referida portaria foi republicada, vetando a implantação de novas ESBs vinculadas somente às EACSs sem que as primeiras tenham sido previamente vinculadas a uma ESF. Assim, fica clara a intenção da Coordenação Nacional de Saúde Bucal em manter a atuação das ESBs nos locais onde foi desabilitada a Equipe de Saúde da Família que lhe deu origem.

Estas duas edições da referida portaria expressam, mais uma vez, a orientação do Governo Federal de aumentar o volume de investimentos voltados para a atenção à saúde bucal desde a publicação da Política Nacional de Saúde Bucal (PNSB), em 2004 (CFO, 2008). Segundo a Coordenação Nacional de Saúde Bucal, esta política, também conhecida como Brasil Sorridente, recebeu, até 2005 , investimentos de mais de $\mathrm{R} \$ 1,2$ bilhão. No ano de 2006, foram investidos mais de $\mathrm{R} \$ 535,2$ milhôes e, em 2007, havia uma expectativa de investimentos da ordem de R\$ 640 milhôes. Para o período entre 2007 e 2010, o montante a ser investido pelo MS deverá alcançar mais de $\mathrm{R} \$ 2,7$ bilhões (CFO, 2008). Portanto, o contínuo e progressivo aumento no volume de investimentos nesta área de atenção à saúde tem sido a tônica do discurso da Coordenação Nacional de Saúde Bucal por todo o período de vigência da PNSB.

Importa considerar que o maior aporte de recursos financeiros destinados à PNSB se fez acompanhar de fato por um maior grau de acesso da população à atenção à saúde bucal, conforme declarado pelo coordenador nacional de Saúde Bucal (PUCCA JUNIOR, 2006). Os recentes trabalhos de Maia (2008) e Maciel (2008) são convergentes face a essa declaração.

Não obstante o reconhecimento comum da importância da ampliação do volume de recursos federais e da ampliação do acesso da população à atenção à saúde bucal, cabe formular a seguinte questão: de que forma e em que medida a 
Portaria no 302, na sua última edição, será capaz de garantir a manutenção do

acesso já conquistado com continuidade do aporte de recursos financeiros para a sustentação das ações e serviços contidos na PNSB?

$\mathrm{O}$ presente artigo descreve e analisa, na perspectiva do financiamento federal, o desenvolvimento da PNSB. Desta forma, serão descritas e discutidas as principais estratégias representadas tanto pela inserção das ESBs na ESF como também a oferta de ações de saúde bucal na média complexidade, através da criação dos Centros de Especialidades Odontológicas (CEOs) e dos Laboratórios Regionais de Prótese Dentária (LRPDs).

Tomando como base a importância da política de incentivos do MS para o financiamento das ações contidas na PNSB, o presente trabalho traça um panorama do financiamento federal voltado para esta área de atenção à saúde. Assim, na primeira parte do texto, são descritas a origem e a evolução do financiamento federal voltado para a saúde bucal, tanto na atenção básica como na média complexidade. Para tanto, foi realizada uma análise das formas de transferências de recursos federais que compõem o financiamento da PNSB. Ainda neste segmento, foi realizado um exercício de análise dos períodos de vigência das Normas Operacionais do Sistema Único de Saúde (SUS) e posteriormente, do Pacto pela Saúde 2006, no que tange ao financiamento federal da PNSB. Finalmente na última seção, "Considerações finais", é feito um esforço de análise prospectiva do desenvolvimento da PNSB frente ao SUS.

\section{A evolução do financiamento federal voltado para a saúde bucal a partir do SUS}

\section{A origem do financiamento federal voltado para a Saúde Bucal}

Em 1996 ocorreu uma mudança na lógica do financiamento da saúde no Brasil, a partir da edição da Norma Operacional Básica (NOB) 96, que criou o Piso da Atenção Básica (PAB). Nesse contexto, os recursos passaram a ser transferidos automaticamente por um valor per capita (PAB fixo) e sob a forma de incentivos (PAB variável), como no caso de programas específicos (BRASIL, 1996). Assim, essa norma, que foi efetivamente implantada em janeiro de 1998, inaugurou um novo modelo de repasse de recursos, uma vez que desvinculou o critério desses repasses da memória financeira da produção de serviços, visando à ampliação do acesso da população aos serviços básicos 
de saúde e, consequentemente, maior equidade na distribuição dos recursos financeiros do SUS (DAIN; FAVERET, 1999; VIANA et al., 2002).

No âmbito da atenção à saúde bucal, até fins da década de 90, não existiam linhas específicas de financiamento de origem federal voltadas para esta área de atenção. Desta forma, os recursos federais destinados ao primeiro nível de atenção em saúde bucal ficavam a cargo dos recursos destinados à atenção básica, e nos níveis subnacionais, segundo os critérios dos gestores locais na elaboração de suas prioridades. É informação relevante o fato de que, nos níveis secundário e terciário de atenção à saúde bucal, o repasse federal era feito apenas com base no volume de procedimentos.

A partir do final do ano 2000, a política de incentivos do MS, através do $\mathrm{PAB}$ variável, passou a financiar a inserção das ESBs no então Programa de Saúde da Família (PSF). Portanto, em consequência, teve início um gradual e considerável aumento no volume de recursos financeiros do nível federal para esta área de atenção a saúde. Este fato representou um grande avanço no sentido do desenvolvimento dos princípios do SUS, pelo menos em duas frentes: do ponto de vista do financiamento, ocorreu uma oferta inédita de recursos específicos de origem federal voltados para esta área de atenção; do ponto de vista do perfil assistencial, favoreceu uma integração pioneira e real da saúde bucal com a política de saúde do país, através do trabalho em equipe levado a termo pelo então PSF.

Em 2004 ocorreu o lançamento do documento Diretrizes da Política Nacional de Saúde Bucal, considerado pela Área Técnica em Saúde Bucal do MS como sendo, de fato, a primeira Política Nacional de Saúde Bucal (PNSB) do SUS. Este processo se deu em um momento particularmente significativo, na medida em que, no plano nacional, a saúde bucal se colocou claramente como prioridade do governo Luiz Inácio Lula da Silva, instalado a partir de 2003. (RONCALLI, 2006; GARCIA, 2006).

As diretrizes da PNSB (2004) apontam, fundamentalmente, para o fortalecimento da atenção básica e para a ampliação da oferta de serviços, assegurando também o atendimento nos níveis secundário e terciário, de modo a buscar integralidade da atenção. Este documento destaca como forma preferencial para a reorganização da atenção básica, o Programa de Saúde da Família (PSF), e inclui uma proposta de política pública de modo a garantir a fluoretação das águas de abastecimento (BRASIL, 2004 a). 
Nesse sentido, podemos dizer que o panorama que se constrói a partir de 2000

do ponto de vista da oferta de recursos é compatível com a maior expressividade adquirida pela saúde bucal na agenda de governo. Veremos a seguir em ordem cronológica a evolução do processo de financiamento federal voltado para a atenção desta área da saúde no SUS.

\section{A evolução do financiamento federal voltado para a Saúde Bucal na Atenção Básica}

A Portaria GM/MS no 1.444, de 28 de dezembro de 2000, estabeleceu incentivos financeiros para a inserção das ESBs no PSF. Entretanto, somente após a edição da Portaria GM/MS no 267, de 06 de março de 2001, foram regulamentadas as normas e diretrizes para a inclusão das ESBs nas suas duas modalidades possíveis de implantação, a saber: modalidade I, composta por $01 \mathrm{CD}$ (cirurgião-dentista) e $01 \mathrm{ACD}^{1}$ (auxiliar de consultório dentário), e modalidade II, composta por 01 CD, 01 ACD e 01 THD (técnico de higiene dentária).

Com a publicação da Portaria no 673/GM, de 2003, os incentivos financeiros de implantação e custeio para ambas as modalidades foram reajustados. Vale registrar que as portarias ministeriais que reajustam os incentivos de implantação os denominam incentivos adicionais. Ademais, a Portaria no 673/GM, de 2003, permitiu uma redução da proporção de implantação, que era até então de uma ESB para cada duas ESFs, para uma relação de 1:1, ou seja: uma ESB para uma ESF.

Em 2004, a Portaria no 74/GM vem estabelecer novos reajustes aos incentivos de custeio mensal para as ESBs, que passaram a receber $\mathrm{R} \$ 1.700,00$ e $\mathrm{R} \$$ 2.400,00, de acordo com a modalidade implantada - I e II, respectivamente. Estes valores correspondem anualmente a $\mathrm{R} \$ 20.400,00$ na modalidade I e a $\mathrm{R} \$$ 26.400,00 na modalidade II. Ademais, esta portaria determinou que as ESBs, a despeito da modalidade de implantação, passassem a receber $\mathrm{R} \$ 6.000,00$ como incentivo adicional para a aquisição de equipamentos e/ou instrumentos. Para as equipes já implantadas, a referida portaria determinou o pagamento de $\mathrm{R} \$ 1.000,00$ em parcela única, como incentivo adicional para a compra dos materiais permanentes utilizados nas fases clínicas de confecção de próteses. Vale registrar que a referida portaria ainda determinou que as ESBs implantadas na modalidade II passassem a receber, por parte do MS um equipo completo ${ }^{2}$ para a atuação do THD. 
Em março de 2006, com a publicação da Portaria no 648/ GM, aprovando e regulamentando a Política Nacional de Atenção Básica, ficou estabelecido que o PSF é a estratégia prioritária do MS para reorganizar a atenção básica e assim este programa passou a ser doravante denominado de Estratégia Saúde da Família (ESF). Ainda em 2006, em maio, a Portaria no 650/ GM reajustou o incentivo adicional das ESBs (modalidades I e II) de $\mathrm{R} \$ 6.000,00$ para $\mathrm{R} \$ 7.000,00$, entendendo-o como um recurso destinado a investimentos nas Unidades Básicas de Saúde e a realização do Curso Introdutório ${ }^{3}$.

Em outubro de 2008, a Portaria no 2.489/GM definiu novos valores de incentivo financeiro para o custeio mensal das ESBs, que assim passaram a receber R\$ 1.900,00 e R\$ 2.450,00 de acordo com a sua modalidade de implantação. Estes valores correspondem anualmente a $\mathrm{R} \$ 22.800,00$ na modalidade I e a $\mathrm{R} \$ 29.400,00$ na modalidade II. A referida portaria lembra ainda que as ESBs implantadas nos municípios constantes do Anexo I da Portaria no 822/GM, ${ }^{4}$ de abril de 2006 , fazem jus a receber $50 \%$ a mais sobre os valores transferidos. $\mathrm{O}$ mesmo acréscimo se aplica às ESBs implantadas nos municípios constantes do Anexo da Portaria no 90/GM, ${ }^{5}$ de janeiro de 2008, que atendam a populaçôes residentes em assentamentos ou remanescentes de quilombos.

É necessário frisar que, em dezembro de 2008 - portanto, dois meses após a edição desta última portaria -, o MS edita outra portaria, a de no 3.066/GM, reajustando mais uma vez os valores dos incentivos federais para o custeio mensal das ESBs. Assim estas equipes passaram a receber R \$ 2.000,00 e R \$ 2.600,00, respectivamente, na dependência da modalidade de implantação. Estes valores correspondem anualmente a $\mathrm{R} \$ 24.000,00$ na modalidade I e a $\mathrm{R} \$ 31.200,00$ na modalidade II.

A Portaria no 302, de fevereiro de 2009, vem estabelecer que as ESBs poderiam ser incorporadas às EACSs, na proporção de 1:1, desde que observados o Capítulo II e o item 3 do Anexo à Portaria no 648/GM6 (2006). Segundo a portaria, os valores dos incentivos financeiros para as ESBs vinculadas à EACS serão transferidos conforme modalidade de implantação da ESB e tendo como base o número de equipes de ACSs com profissionais de saúde bucal cadastrados no Sistema de Cadastro Nacional de Estabelecimentos de Saúde (SCNES).

Em abril de 2009, esta portaria foi republicada com a seguinte alteração: "Fica vetada a implantação de equipes novas de Saúde Bucal vinculadas somente 
a equipes de Agentes Comunitários de Saúde sem que tenham sido previamente

vinculadas a uma equipe de Saúde da Família” (BRASIL, 2009 a). As portarias supracitadas, que descrevem a modalidade de implantação, composição e valores dos incentivos e seus reajustes estão sintetizadas no quadro 1 .

Quadro 1: Composição das equipes, portarias de implantação e de custeio anual e seus correspondentes valores de incentivo

\begin{tabular}{|c|c|c|c|c|c|c|c|c|c|}
\hline $\begin{array}{l}\text { Mod. } \\
\text { Impl. } \\
\text { das } \\
\text { ESBS }\end{array}$ & 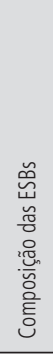 & 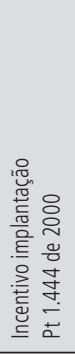 & 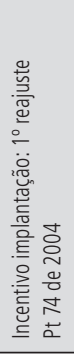 & 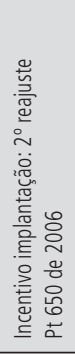 & 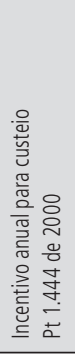 & 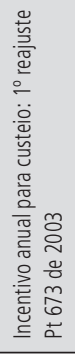 & 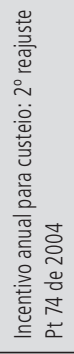 & 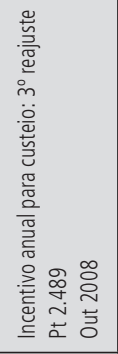 & 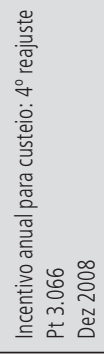 \\
\hline Mod. I & 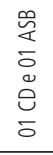 & 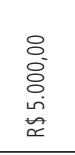 & $\begin{array}{l}0 \\
0 \\
0 \\
0 \\
0 \\
\infty\end{array}$ & 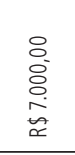 & 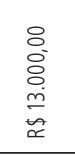 & 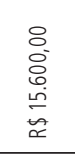 & 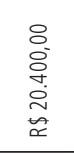 & 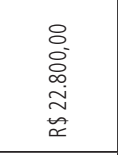 & 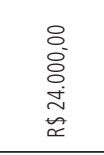 \\
\hline Mod. II & 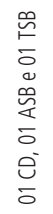 & 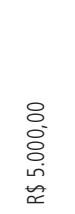 & $\begin{array}{l}0 \\
0 \\
0 \\
0 \\
0 \\
\text { 心 }\end{array}$ & 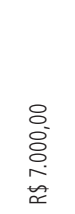 & 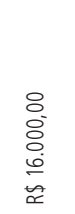 & 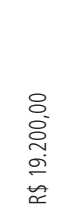 & 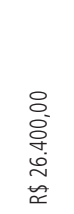 & 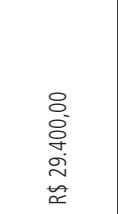 & 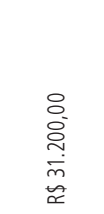 \\
\hline
\end{tabular}

Legenda: CD (cirurgião-dentista) ASB (auxiliar de saúde bucal) e TSB (técnico de saúde bucal). Fonte: Elaboração própria a partir das Portarias: GM/MS no 267 de 2001, GM/MS no 1.444 de 2000, GM/MS no 673 de 2003, GM/MS no 74 de 2004 e GM/MS no 650.

\section{A evolução do financiamento federal voltado para a Saúde bucal na Média Complexidade}

O perfil assistencial da saúde bucal no país atéos anos 2000 foi fundamentalmente marcado pela oferta reduzida de açôes, de baixa complexidade, de caráter predominantemente curativo e mutilador. Além disso, essa assistência esteve dirigida preferencialmente à faixa etária escolar, ou seja, para crianças de 6 a 12 anos de idade. Aos adultos e aos idosos o acesso resumia-se, via de regra, aos serviços de urgência, nos quais a resolutividade dos problemas frequentemente resultava em exodontias ${ }^{7}$ (BRASIL, 2006c; MAIA, 2008). O modelo de atenção à saúde bucal, como descrito acima, operava com uma base limitada de recursos financeiros. 
No curso da década de 2000, o MS, atento à necessidade de superação da lacuna existente nesta área de atenção, passou a destinar incentivos financeiros para a inclusão da saúde bucal no então PSF. No entanto, ainda permaneciam deficiências na oferta da atenção à saúde bucal: serviços de maior complexidade continuavam limitados a uma oferta restrita, carente de diretrizes e incentivos de ordem federal (MAIA, 2008).

Em 2003, o MS, através da Área Técnica em Saúde Bucal, publicou os resultados do Levantamento de Condiçôes da Saúde Bucal da População Brasileira ${ }^{8}$ (SB-2003). Os dados apontaram que $27 \%$ das crianças de 18 a 36 meses e $60 \%$ das crianças de cinco anos de idade já apresentavam pelo menos um dente com experiência de cárie. Entre os adultos de 35 a 44 anos, 28\% apresentaram edentulismo 9 ou indicação para exodontia. Para a faixa etária de 65 a 74 anos, a média de elementos dentários presentes na boca foi de apenas seis dentes por pessoa, sendo que três entre cada quatro destes idosos já não possuíam nenhum dente funcional, ou seja, em condições de exercer suas funções de mastigação, fonação e estética (MAIA, 2008).

Nesse contexto, os resultados do SB-2003 tornaram evidentes as necessidades de ações de maior complexidade voltadas para superar a grave situação da oferta de assistência oferecida pelos serviços públicos de saúde no Brasil até então. Além da necessidade de se ofertar soluções para esta questão, desigualdades no acesso a outros serviços odontológicos de maior complexidade no âmbito do SUS foram também reveladas pelo SB 2003 (BRASIL, 2003 a).

Em 2004, com o lançamento do documento Diretrizes da Política Nacional de Saúde Bucal (PNSB), teve início o repasse dos recursos financeiros para incentivo de ações em saúde bucal de média complexidade, através da implantação e custeio mensal dos Centros de Especialidades Odontológicas (CEOs) e para a remuneração de próteses dentárias confeccionadas nos Laboratórios Regionais de Próteses Dentárias (LRPDs). A criação tanto dos CEOs como do LRPDs e as novas formas de repasse financeiro federal voltadas para estes serviços foram vistas como uma inovação apta a reverter o grave quadro acima exposto (BRASIL, 2004 a).

Em 2006 foram publicadas as portarias que definiram os critérios, normas e requisitos para a implantação dos CEOs e LRPDs, e instituem seu financiamento (BRASIL, 2006b; BRASIL, 2006d; BRASIL, 2006e). Para a implantação e custeio dos CEOs, o MS passou a garantir incentivos financeiros de acordo com 
os planos municipais e regionais de cada estado. No entanto, o repasse federal representa apenas uma parte dos recursos necessários ao custeio dos CEOs, cabendo aos estados e aos municípios a responsabilidade da complementação do custeio desses serviços.

Assim, existem três modalidades possíveis de habilitação, dependendo do número de equipos disponíveis nos serviços, como exposto no quadro a seguir.

Quadro 2: Incentivos federais por tipo de CEO

\begin{tabular}{|c|c|c|c|}
\hline $\begin{array}{c}\text { Tipo de } \\
\text { CEO }\end{array}$ & $\begin{array}{c}\text { No de Equipos } \\
\text { (Cadeiras) }\end{array}$ & $\begin{array}{c}\text { Incentivo de } \\
\text { implantação }\end{array}$ & $\begin{array}{c}\text { Incentivo mensal } \\
\text { para custeio }\end{array}$ \\
\hline I & 03 & $40.000,00$ & $6.600,00$ \\
\hline II & De 04 a 06 & $50.000,00$ & $8.800,00$ \\
\hline III & 07 ou mais & $80.000,00$ & $15.400,00$ \\
\hline
\end{tabular}

Fonte: Maia, L.S, 2008 a partir da Portaria GM/MS no 600 de 23/03/2006.

Ainda no âmbito dos CEOs, o MS condicionou o seu repasse financeiro de custeio a uma produção mensal mínima de procedimentos ambulatoriais a ser verificada através do Sistema de Informação Ambulatorial do SUS (SIA SUS).${ }^{11}$ A produção mensal cobrada pelo MS está relacionada ao tipo de CEO, e é específica para cada uma das especialidades obrigatórias. Desta forma, para o CEO tipo I, é necessária a realização de 80 procedimentos em dentística básica; $60 \mathrm{em}$ periodontia; 35 em endodontia e 80 em cirurgia oral menor. Para o CEO tipo II, é preciso produzir 110 procedimentos em dentística básica; $90 \mathrm{em}$ periodontia; 60 em endodontia e 90 em cirurgia oral menor. Já para o CEO tipo III, são necessários 190 procedimentos em dentística básica; 150 em periodontia; 95 em endodontia e 170 em cirurgia oral menor (BRASIL, $2006 \mathrm{~d}$ ).

Além dos incentivos de custeio, as ações realizadas nos CEOs são faturadas pela tabela de procedimentos SIA/SUS e remuneradas de acordo com os tetos financeiros de cada ente federado (MAIA, 2008).

No tocante à reabilitação protética, o pagamento das próteses dentárias aos LRPDs, de acordo com a Portaria no 1572/GM, de 29 de julho de 2004, se dá por produção. O MS estabeleceu limites para o pagamento mensal das próteses confeccionadas nos LRPDs: o limite mínimo é de 40 próteses parciais e 48 próteses totais (dentaduras). Essa mesma portaria estabelece que, para os LRPDs ${ }^{12}$ 
localizados nos CEOs, a exigência da produção mensal mínima é de apenas 40 próteses totais. No tocante aos limites máximos, a portaria citada estabelece um total de 242 próteses por mês. O quantitativo excedente, se ocorrer, deverá ser de inteira responsabilidade dos gestores locais. Os recursos financeiros $(\mathrm{R} \$$ 30,00 próteses parciais) e ( $\mathrm{R} \$ 40,00$ próteses totais) são repassados diretamente do Governo Federal para os municípios ou estados que possuem laboratórios credenciados, não comprometendo seus recursos de saúde já existentes.

Apesar da recomendação do MS para que a oferta das próteses ocorra no âmbito da atenção básica, os valores de remuneração das mesmas são faturados por Autorização de Procedimento de Alto Custo/Complexidade (APAC) e financiados pelo Fundo de Ações Estratégicas e Compensação (FAEC) (MAIA, 2008).

$\mathrm{O}$ processo até aqui descrito torna evidente o propósito do MS em conduzir a normatização da atenção à saúde bucal no âmbito do SUS de acordo com os moldes preconizados pela PNSB. Em síntese, conforme já visto nos itens anteriores, o financiamento da saúde bucal através de incentivos federais se inicia em 2000, no âmbito da atenção básica, com a inserção das ESBs no então PSF, e na atenção secundária em 2004, com os repasses financeiros para a implantação e custeio dos CEOs e dos LRPDs. Sendo assim, no que tange ao aporte de recursos federais na forma de incentivos, também na média complexidade se reproduziu a mesma característica ocorrida na atenção básica: o aumento contínuo e crescente de recursos financeiros.

Este processo de reorganização da atenção à saúde bucal atravessou dois governos de orientação política e ideológica, a princípio, bastante distintas. Além disso, transcorreu através de uma clara sequência de portarias, que representam atos administrativos gerados a partir do Poder Executivo, o que lhe conferiu uma capacidade de contínua atualização e aprofundamento de suas modalidades de ação.

\section{O esgotamento do ciclo das normas operacionais e a emergência do Pacto pela Saúde de 2006}

Em 2006, o Ministério da Saúde, através da Portaria no 399/GM, de 22 de fevereiro de 2006, instituiu o documento Pacto pela Saúde 2006. Este compreende, na verdade, três pactos: Pacto pela Vida, Pacto em Defesa do SUS e o Pacto de Gestão, e veio a substituir a Norma Operacional de Assistência à Saúde, de 2002 (NOAS 2002). 
O Pacto pela Saúde de 2006, através da Portaria no 698/GM, de 30 de março

de 2006, alterou a forma de financiamento do SUS, eliminando mais de cem modalidades de transferências de recursos, reduzindo-as a apenas cinco blocos. No entanto, os recursos para a sustentação da PNSB estão garantidos em três destes blocos: Atenção Básica, Gestão e Média e Alta Complexidade (BRASIL, 2006 a).

Em abril de 2009, o MS editou a Portaria GM no 837, que insere o sexto bloco de financiamento, denominado Bloco de Investimentos na Rede de Serviços de Saúde. Este é composto por recursos voltados exclusivamente para a realização de despesas de capital condicionados a apresentaçōes de projetos pelos entes subnacionais. Estes projetos, uma vez aprovados pela Comissão Intergestores Bipartite (CIB) de cada estado, serão encaminhados ao MS. A transferência dos recursos relativos a esta portaria deverá ser regulamentada através de uma nova portaria específica a ser editada pelo MS (BRASIL, 2009 b).

Assim, no âmbito da atenção à saúde bucal, a partir do Pacto de 2006 os recursos destinados às ESBs na ESF estão incluídos no bloco da Atenção Básica, dentro do PAB variável (BRASIL, 2006 a). O bloco de Gestão custeia ações relacionadas à organização e ampliação do acesso aos serviços de saúde, nas quais se inclui a implantação dos CEOs. O bloco da Média e Alta Complexidade compreende um incentivo permanente para os CEOs e para os LRPDs. Contudo, apesar do fato de o financiamento da saúde ter sido alterado pelo Pacto pela Saúde 2006, a limitada adesão dos municípios a este pacto faz com que a operacionalização do financiamento da saúde, o que inclui o da saúde bucal, se mantenha, na maioria dos municípios, ainda como descrito anteriormente.

Em síntese, no que diz respeito ao financiamento, as inovações trazidas pelo Pacto de Gestão 2006 são capazes de gerar maior autonomia do gestor local no emprego dos recursos financeiros. No entanto, no que diz respeito à atenção a saúde bucal, essas mudanças não alteraram as linhas de financiamento federal anteriormente existentes.

\section{Considerações finais}

A questão formulada no início do presente trabalho nos levou a realizar primeiramente uma análise da evolução e da progressão do aporte financeiro federal voltado para a atenção à saúde bucal no âmbito do SUS. Apesar do significativo crescimento do volume de recursos financeiros especificamente 
voltados para esta área de atenção à saúde, que proporcionaram a ampliação do acesso aos serviços e as ações contidas na PNSB, a continuidade e a sustentação desta política podem não ser uma consequência natural deste processo.

De acordo com os dados disponibilizados tanto pelo Departamento de Atenção Básica (DAB-MS) como pelo Sistema de Informação do SUS (DATASUSMS), de um modo geral, de fato ocorreu um aumento tanto no acesso como na assistência à saúde bucal no âmbito do SUS a partir de 2001, com a implantação das ESBs na ESF.

A entrada da PNSB na agenda do governo, embora expressa pelo aumento significativo do volume de investimentos, condiciona o repasse destes recursos financeiros na atenção básica à adesão dos gestores locais às ESBs na ESF, e no âmbito da atenção secundária, aos CEOs e LRPDs. Noutros termos, fora dos padrões preconizados pelas normas e portarias que regulamentam o SUS, não existe financiamento extraorçamentário para a sustentação das ações de saúde bucal nos dois níveis de atenção supracitados, ficando este diretamente condicionado ao $\mathrm{PAB}$ fixo e à política de incentivo do MS para o financiamento e sustentação desta estratégia.

Ademais, os incentivos federais voltados para a sustentação financeira da PNSB, ainda que de importância capital, não podem prescindir das contrapartidas dos níveis subnacionais, conforme previsto na Emenda Constitucional $29^{13}$. Assim, a sustentabilidade da oferta das ações e serviços inseridos na PNSB pressupõe a adesão a um conjunto de diretrizes onde se inserem a descentralização e a responsabilização dos gestores locais na provisão e na continuidade desta oferta.

Ainda que os recursos federais destinados à implantação e ao custeio das ações previstas na PNSB representem um importante fator de indução para a adesão pelos gestores locais a esta política, estes recursos por si só não são capazes de garantir a oferta dessas ações e serviços de modo a contemplar as demandas em saúde bucal da população. No tocante à saúde bucal, frente a outras áreas de atenção à saúde, ainda existem custos adicionais relativos à manutenção de equipamentos, instrumentais, insumos e materiais de consumo específicos, sabidamente onerosos.

Portanto, no balanço da última década, a prestação pública de serviços em saúde bucal avança de um panorama de oferta limitada de procedimentos de baixa complexidade com reduzida realização de procedimentos especializados, 
em direção à ampliação do acesso na atenção básica e na média complexidade.

Essa ampliação se deu tanto no sentido da universalização quanto da integralidade das ações. No entanto, para que haja sustentabilidade das ações, é imprescindível que a lógica desta oferta se mantenha consonante com as normas e diretrizes vigentes do SUS.

Desta forma, ao se manter a atual configuração da Portaria no 302, que permite a manutenção ESBs não mais vinculadas à ESF, se contrariam as referidas diretrizes voltadas para a reorganização da atenção básica. Essas diretrizes, contidas no documento Política Nacional de Atenção Básica (regulamentadas pela Portaria n648, de 2006) explicitam que a atenção básica deverá ser desenvolvida sob a forma de trabalho em equipe, orientado "pelos princípios da universalidade, da acessibilidade e da coordenação do cuidado, do vínculo e continuidade, da integralidade, da responsabilização, da humanização, da equidade e da participação social" (BRASIL, 2006 f).

Nesse sentido, consideramos que a referida portaria pode representar um retrocesso frente ao avanço conquistado em 2000, no que tange ao processo de reorganização da oferta assistencial por ocasião da inclusão saúde bucal na lógica do trabalho em equipe realizado pela ESF. E ainda, em relação a seu financiamento, este fato poderá comprometer a continuidade da oferta de recursos financeiros federais sob a forma de incentivos para sua sustentação, já que estes são atrelados à ESF. Ademais, futuros investimentos no sentido da qualificação e da avaliação da oferta de ações e serviços contidos na PNSB poderão ser comprometidos. O risco de um desfinanciamento federal para a saúde bucal no nível básico de atenção poderá ainda acarretar a descontinuidade desta oferta especialmente naqueles locais onde os incentivos federais foram indutores da adesão e implantação das ESBs.

Destacamos ainda que a saúde bucal é a única área de atenção à saúde que conta com recursos oriundos da política de incentivos do MS voltados para custeio mensal de açôes de média complexidade através dos CEOs, unidades ambulatoriais de referência preferencial para as ESBs na ESF. Da mesma forma, é importante ressaltar que o repasse de recursos financeiros federais para estes serviços está condicionado a uma produção mínima mensal e que esta obrigatoriedade de produção está diretamente relacionada aos procedimentos realizados na atenção básica, sendo a atenção secundária um complemento da primeira. Assim, por consequência, o repasse de recursos federais para o custeio 
mensal dos CEOs também poderá ser negativamente afetado, comprometendo mais uma vez a sustentação das ações e serviços preconizados pela PNSB.

Os esforços na busca pela consolidação da PNSB, além de considerar a ampliação do acesso e a garantia da continuidade dos incentivos financeiros, devem estar consoantes com as diretrizes da Política Nacional de Atenção Básica, especialmente no que diz respeito à reorganização desse nível de atenção (BRASIL, 2006 f).

Finalmente, é preciso ter presente que ao tentar garantir repasses de recursos federais para a manutenção das ESBs fora da Estratégia de Saúde da Família, a Portaria no 302 pode colocar em risco não só o financiamento da atenção a saúde bucal a partir da política de incentivos do MS, mas também a própria continuidade da garantia do acesso já conquistado, tanto na atenção básica como na média complexidade.

\section{Referências}

ASSOCIAÇÃO PAULISTA DE CIRURGIŌES DENTISTAS. Jornal. Ano 43, n. 624, p. 16, abril 2009.

BRASIL. Ministério da Saúde. Secretaria Nacional de Programas Especiais de Saúde. Política Nacional de Saúde Bucal. Princípios, objetivos, prioridades. Brasília: Divisão Nacional de Saúde Bucal, 1989. 24p.

. Ministério da Saúde. Norma Operacional Básica do Sistema Único de Saúde (NOBSUS/96). Brasília: Ministério da Saúde, 1996.

. Ministério da Saúde. Portaria GM/MS no 1444, de 28 de dezembro de 2000. Estabelece incentivo financeiro para a reorganização da atenção à saúde bucal prestada nos municípios por meio do Programa de Saúde da Família. Brasília: Ministério da Saúde, 2000.

Ministério da Saúde. Portaria GM/MS no 723, de 14 de maio de 2001. Pacto de Indicadores da Atenção Básica. Indicadores a serem Pactuados pelos estados. Brasília: Ministério da Saúde, 2001.

. Ministério da Saúde. Portaria GM/ MS no 267, de 06 de março de 2001. Define as Diretrizes e Normas da inclusão das ações de saúde bucal no PSF. Brasília: Ministério da Saúde, 2001.

. Ministério da Saúde. Norma Operacional da Assistência à Saúde (NOAS-SUS 01/02). Regionalização da Assistência à Saúde: aprofundando a descentralização com equidade no acesso. Brasília: Ministério da Saúde, 2002. 

pesquisa "Condições de Saúde Bucal da População Brasileira - Projeto SB Brasil 2003". Brasília: Ministério da Saúde, 2003 a. Disponível em <www.saúde.gov.br> . Acesso em: ago. 2006.

. Ministério da Saúde. Portaria GM/MS nº 673, de 03 de junho de 2003. Reajusta os valores dos incentivos financeiros aos Programas de Saúde da Família, de Agentes Comunitários de Saúde e às Ações de saúde bucal no âmbito do Programa Saúde da Família e dá outras providências. Brasília: Ministério da Saúde, 2003.

- Ministério da Saúde. Secretaria de Atenção à Saúde. Departamento de Atenção Básica. Coordenação Nacional de Saúde Bucal. Diretrizes da Política Nacional de Saúde Bucal. Brasília: Ministério da Saúde, 2004a.

. Ministério da Saúde. Portaria GM/MS no 74, de 20 de janeiro de 2004. Reajusta os valores dos incentivos financeiros às Ações de saúde bucal no âmbito do Programa Saúde da Família, inclui procedimentos de moldagem para prótese e dá outras providências. Brasília: Ministério da Saúde, 2004.

. Ministério da Saúde. Portaria GM/MS no 1570, de 29 de julho de 2004. Estabelece critérios, normas e requisitos para a implantação e habilitação dos Centros de Especialidades Odontológicas e Laboratórios Regionais de Próteses Dentárias. Brasília: Ministério da Saúde, 2004.

. Ministério da Saúde. Portaria GM/MS no 1572, de 29 de julho de 2004. Estabelece o pagamento de próteses dentárias totais em Laboratórios Regionais de Próteses Dentárias. Brasília: Ministério da Saúde, 2004.

Ministério da Saúde. Portaria GM/MS no 283, de 22 de março de 2005. Antecipa do incentivo financeiro para Centros de Especialidades Odontológicas (CEO) em fase de implantação, e dá outras providências. Brasília: Ministério da Saúde, 2005.

Ministério da Saúde. A Implantação da EC 29: Apresentação dos dados do SIOPS, 2000 a 2003. Texto elaborado pela Equipe SIOPS/ DES/ SCTIE/ Ministério da Saúde. Brasília, 2005. Disponível em: <http://siops.datasus.gov.br/Documentacao/ Implanta\%C3\%A7\%C3\%A3o_EC_29_dados_SIOPS.PDF> Acesso em: 12 mar. 2007.

Ministério da Saúde. Portaria GM/MS no 399, de 22 de fevereiro de 2006. Divulga o Pacto pela Saúde 2006 - Consolidação do SUS e aprova as Diretrizes Operacionais do Referido Pacto. Brasília: Ministério da Saúde, 2006a.

Ministério da Saúde. Portaria GM/MS nº 599, de 23 de março de 2006. Define a implantação de Especialidades Odontológicas e de Laboratórios Regionais de Próteses Dentárias e estabelecer critérios, normas e requisitos para seu credenciamento. Brasília: Ministério da Saúde, 2006b.

- Ministério da Saúde. Secretaria de Atenção à Saúde. Departamento de Atenção Básica. Cadernos de Atenção Básica no 17. Saúde Bucal. Série A. Normas e Manuais Técnicos. Brasília: Ministério da Saúde, 2006c. 

o financiamento dos Centros de Especialidades Odontológicas. Brasília: Ministério da Saúde, 2006d.

Ministério da Saúde. Portaria GM/MS nº 698, de 30 de março de 2006. Define que o custeio das ações de saúde é de responsabilidade das três esferas de gestão do SUS, observado o disposto na Constituição Federal e na Lei Orgânica do SUS. Brasília: Ministério da Saúde, 2006e.

Ministério da Saúde. Portaria GM/MS no 648, de 28 de março de 2006. Aprova a Política Nacional de Atenção Básica, estabelecendo a revisão de diretrizes e normas para a organização da Atenção Básica para o Programa Saúde da Família (PSF) e o Programa Agentes Comunitários de Saúde (PACS). Brasília: Ministério da Saúde, 2006f.

. Ministério da Saúde. Portaria GM/MS nº 650, de 28 de março de 2006. Define valores de financiamento do $\mathrm{PAB}$ fixo e variável mediante a revisão de diretrizes e normas para a organização da Atenção Básica, para a estratégia de Saúde da Família e para o Programa de Agentes Comunitários de Saúde, instituídos pela Política Nacional de Atenção Básica. Brasília: Ministério da Saúde, 2006.

. Ministério da Saúde. Portaria GM/MS no 822, de 17 de abril de 2006. Altera critérios para definição de modalidades das ESF dispostos na Política Nacional de Atenção Básica. Brasília: Ministério da Saúde, 2006.

. Ministério da Saúde. Portaria GM/MS no 204, de 29 de janeiro de 2007. Regulamenta o financiamento e a transferência dos recursos federais para as ações e os serviços de saúde, na forma de blocos de financiamento, com o respectivo monitoramento e controle. Brasília: Ministério da Saúde, 2007.

. Ministério da Saúde. Portaria GM/MS n 2.489, de 21 de outubro de 2008. Define valores de financiamento do Piso da Atenção Básica Variável para a estratégia de Saúde da Família e de Saúde Bucal, instituídos pela Política Nacional de Atenção Básica. Brasília: Ministério da Saúde, 2008a.

Ministério da Saúde. Portaria GM/MS nº 3.066, de 23 de dezembro de 2008. Define valores de financiamento do Piso da Atenção Básica Variável para a estratégia de Saúde da Família e de Saúde Bucal, instituídos pela Política Nacional de Atenção Básica. Brasília: Ministério da Saúde, 2008b.

Ministério da Saúde. Portaria GM/MS no 302, de 17 de fevereiro de 2009. Estabelece que profissionais de Saúde Bucal da Estratégia Saúde da Família poderão ser incorporados às Equipes de Agentes Comunitários de Saúde (EACS). Brasília: Ministério da Saúde, 2009a.

Ministério da Saúde. Portaria GM/MS no 837, de 23 de abril de 2009. Altera e acrescenta dispositivos à Portaria n ${ }^{\circ}$ 204/GM, de 29 de janeiro de 2007, para inserir o Bloco de Investimentos na Rede de Serviços de Saúde na composição dos blocos de financiamento 
relativos à transferência de recursos federais para as ações e os serviços de saúde no âmbito do Sistema Único de Saúde (SUS). Brasília: Ministério da Saúde, 2009b.

CONSELHO FEDERAL DE ODONTOLOGIA. Pacto pela Saúde Bucal. Jornal do CFO. Ano 16, n. 83, mar-abr 2008. Disponível em: http://www.cfo.org.br/jornal/n83/cfo44anos03.asp Acesso em: ago 2008.

DAIN, S.; FAVERET, A.C. de S.C. Entre o Neofederalismo e o Ornitorrinco: relações intergovernamentais no Brasil. Rev. Inteligência, Rio de Janeiro, v. 2, p. 43-52, 10 set. 1999. GARCIA, D. do V. A construção da política nacional de saúde bucal: percorrendo os bastidores do processo de formulação. 2006. 104 p. Dissertação (Mestrado em Saúde Coletiva) - Instituto de Medicina Social, Universidade do Estado do Rio de Janeiro, Rio de Janeiro, 2006.

LIMA, L.D. Federalismo, Relaçôes Fiscais e Financiamento do Sistema Único de Saúde: a distribuição de receitas vinculadas à saúde nos orçamentos municipais e estaduais. 2006408 p. Tese (Doutorado em Saúde Coletiva) - Instituto de Medicina Social, Universidade do Estado do Rio de Janeiro, Rio de Janeiro, 2006.

MAIA, L.S: Política Nacional de Saúde Bucal: uma análise da reorganização da atenção à saúde bucal no Estado do Rio de Janeiro frente aos incentivos federais. 2008. 213 p. Dissertação (Mestrado em Saúde Coletiva) - Instituto de Medicina Social, Universidade do Estado do Rio de Janeiro, Rio de Janeiro, 2008.

MACIEL, Sérgio Murta: A presença da ortodontia no SUS: a experiência dos CEOs e de outros serviços públicos de saúde bucal. 2008. 203 p. Tese (Doutorado em Saúde Coletiva) Instituto de Medicina Social. Universidade do Estado do Rio de Janeiro. Rio de Janeiro, 2008. PUCCA JUNIOR, G.A. A política nacional de saúde bucal como demanda social. Rev Cienc. Saúde Coletiva, Rio de Janeiro, v. 11, n. 1, p. 243-246, jan-mar 2006.

RONCALLI, A.G. Epidemiologia e saúde bucal coletiva: um caminhar compartilhado. Rev Cienc. Saúde Coletiva, Rio de Janeiro, v. 11, n. 1, p. 105-114, jan-mar 2006.

VIANA, A.L.; LIMA, L.D; OLIVEIRA, R.G.. Descentralização e federalismo: a política de saúde em novo contexto-lições do caso brasileiro. Rev Cienc. Saúde Coletiva, Rio de Janeiro, v. 7, n. 3, p. 493-507, 2002.

ZANETTI, C.H.G. As marcas de mal-estar social no sistema nacional de saúde tardio: o caso das políticas de saúde bucal no Brasil dos anos 80. 1993. 294 p. Dissertação (Mestrado em Saúde Pública) - Departamento de Ciências Sociais, Escola Nacional de Saúde Pública, Fundação Oswaldo Cruz, Rio de Janeiro, 1993.

\section{Notas}

${ }^{1}$ A Lei Federal no 11.889, de dezembro de 2008, regulamentou o exercício das profissões de Auxiliar em Saúde Bucal (ASB), anteriormente denominado ACD, e de Técnico em Saúde Bucal (TSB), anteriormente denominado THD. 
${ }^{2}$ A Portaria no 74 GM/MS, de 20 de janeiro de 2004, considera como equipo odontológico completo: 01 cadeira, 01 equipo de 3 pontas, 01 unidade auxiliar, 01 mocho e 01 refletor.

${ }^{3} \mathrm{O}$ MS, tomando por base o estabelecimento de diretrizes pedagógicas nacionais que facilitem o processo de capacitação dos profissionais da Saúde da Família, torna obrigatório para todos os profissionais que integram as Equipes de Saúde da Família o "Curso Introdutório". A Portaria GM/MS no 2527, de 19 de outubro de 2006, além de definir os conteúdos mínimos do curso, define também uma carga horária mínima de 40 horas para certificação dos profissionais que integram as ESFs (MAIA, 2008).

${ }^{4}$ Os municípios com população de até 50 mil habitantes nos estados da Amazônia Legal, ou com população até 30 mil habitantes e Índice de Desenvolvimento Humano (IDH) igual ou inferior a 0,7 nos demais estados. Da mesma forma, fazem jus ao acréscimo de 50\%as ESFs implantadas em municípios não incluídos no estabelecido na alínea I, mas que atendam à população remanescente de quilombos e/ou residente em assentamentos de no mínimo 70 (setenta) pessoas, respeitado o número máximo de equipes por município, publicado em portaria específica.

${ }^{5}$ Atualiza o quantitativo populacional de residentes em assentamentos da reforma agrária e de remanescentes de quilombos, por município, para cálculo do teto de Equipes Saúde da Família, modalidade I, e de Equipes de Saúde Bucal da estratégia Saúde da Família.

${ }^{6}$ A Portaria No 648/GM, de 28 de março de 2006, aprova a Política Nacional de Atenção Básica, estabelecendo a revisão de diretrizes e normas para a organização da Atenção Básica para o Programa Saúde da Família (PSF) e o Programa Agentes Comunitários de Saúde (PACS). O Item 3 - do capitulo II trata da infraestrutura e dos recursos necessários à incorporação de profissionais de saúde bucal nas Equipes de Saúde da Família. A adoção destes critérios deve ser também respeitada na incorporação das ESBs às EACSs.

${ }^{7} \mathrm{O}$ termo exodontia (ou extração) significa remoção cirúrgica do elemento dentário.

${ }^{8}$ O Senso Bucal 2000, ou SB 2000, foi o maior e mais amplo levantamento em saúde bucal feito em no Brasil, tendo sido finalizado em 2003. Reuniu, ao todo, informações de mais de 100 mil exames, realizados em todas as regiōes do país, alcançando pela primeira vez municípios de pequeno porte e áreas rurais. Avaliou a maioria dos agravos mais importantes da saúde bucal, e contou com uma composição de grupos etários que engloba todos os ciclos de vida. (BRASIL, 2003; RONCALLI, 2006). ${ }^{9} \mathrm{O}$ termo edentulismo significa a ausência total dos elementos dentários na cavidade oral.

${ }^{10}$ Os procedimentos de moldagem, adaptação e acompanhamento das próteses dentárias são considerados pelo MS como integrantes da fase clínica do tratamento e, portanto, são contabilizados no SIA/ SUS como procedimentos da atenção básica. Contudo, a fase laboratorial de confecção é considerada como procedimento de alto custo/complexidade, sendo seu pagamento feito através de Autorização de Procedimento de Alto Custo/Complexidade (APAC) (MAIA, 2008).

${ }^{11}$ Em 2008, para fins de remuneração, os procedimentos ambulatoriais no âmbito do SUS passaram a integrar uma tabela única.

${ }^{12}$ Os LRPDs podem se situar no âmbito dos CEOs ou não. Ademais podem ser ainda terceirizados.

${ }^{13}$ A Emenda Constitucional 29 foi regulamentada no Senado Federal em abril de 2008 e aguarda sua aprovação na Câmara Federal e Presidência da República. 
Dental care financing evolution in the SUS: analysis of the process of health care reorganization in relation to federal incentives This paper describes and analyzes, in the perspective of federal financing, the development of the so called Política Nacional de Saúde Bucal (PNSB) [Dental Care National Politics]. It considers the progress of improvement of access provided by the inclusion of Dental Care Teams (DCT) in the Family Health Strategy (FHS), and the creation of Odontological Specialties Centers (OEC) and Regional Laboratories of Dental Prostheses (RLDP). Despite the importance of such improvement, this paper aims to reflect on the following issue: how the Decree $302 / 2009$, that disengages DCT from FHS, is able to ensure the already achieved access with continuing financial resources? So a bibliographical and documental analysis was conducted, comprising the issue of SUS Operational Norms until the 2006 Health Pact. In the final remarks, the authors point out that most part of financial resources for dental care coincides with the policies adopted by the Health Ministry in the 1990's: primary care re-organization through the Family Health Strategy, and the incentives politics, as a way of transferring federal resources. Also, they highlight the risk of retreat brought by this decree, as it jeopardizes both the primary care re-organization process in dental care, and its financing, once the incentives politics of the Health Ministry is concerned with the Family Health Strategy.

> Key words: Dental care, SUS, health politics, Dental Care National Politics. 